\title{
PCR-Restriction Fragment Length Polymorphism Analysis of Genes Coding for 16S rRNA in Veillonella spp.
}

\author{
TAKUICHI SATO, ${ }^{1 *}$ MICHIKO SATO,${ }^{1}$ JUNKO MATSUYAMA, $^{2}$ AND ETSURO HOSHINO ${ }^{1}$ \\ Departments of Oral Microbiology ${ }^{1}$ and Pediatric Dentistry, ${ }^{2}$ Niigata University \\ School of Dentistry, Gakkocho-dori 2, Niigata 951, Japan
}

\begin{abstract}
Restriction fragment length polymorphism analysis of PCR-amplified 16S ribosomal DNA (16S rDNA PCRRFLP) was used to generate restriction profiles of the American Type Culture Collection type strains of the genus Veillonella, i.e., $V$. atypica, $V$. caviae, $V$. criceti, $V$. dispar, $V$. parvula, $V$. ratti, and $V$, rodentium. Whole-cell protein profiles were obtained by sodium dodecyl sulfate-polyacrylamide gel electrophoresis for comparative purposes. The $16 \mathrm{~S}$ rRNA genes were amplified by PCR, and RFLP analysis of the 16S rDNA was performed with $M n l I$ and Sau3AI. MnlI produced six RFLP patterns for seven type strains, since the patterns for $V$. atypica and $V$. caviae were the same. RFLP patterns with Sau3AI could distinguish between $V$. atypica and $V$. caviae. The type strains of Veillonella species were easily distinguished by 16S rDNA PCR-RFLP.
\end{abstract}

The genus Veillonella consists of small, nonfermentative, anaerobic, gram-negative cocci that normally inhabit the mouths and respiratory and intestinal tracts of humans and animals $(9,10)$. Since Veillonella species obtain their energy by fermenting organic acids, e.g., pyruvate and lactate, this metabolism has the potential to remove a potent, dental-cariesproducing acid. Thus, the presence of Veillonella cells in dental plaque samples may reduce the caries-producing potential of the organisms in the plaque (10).

Veillonella species, i.e., $V$. atypica, $V$. caviae, $V$. criceti, $V$. dispar, $V$. parvula, $V$. ratti, and $V$. rodentium, can be distinguished by DNA-DNA hybridization $(5,9)$, and some of these, i.e., $V$. atypica, $V$. dispar, $V$. parvula, and $V$. ratti, have also been

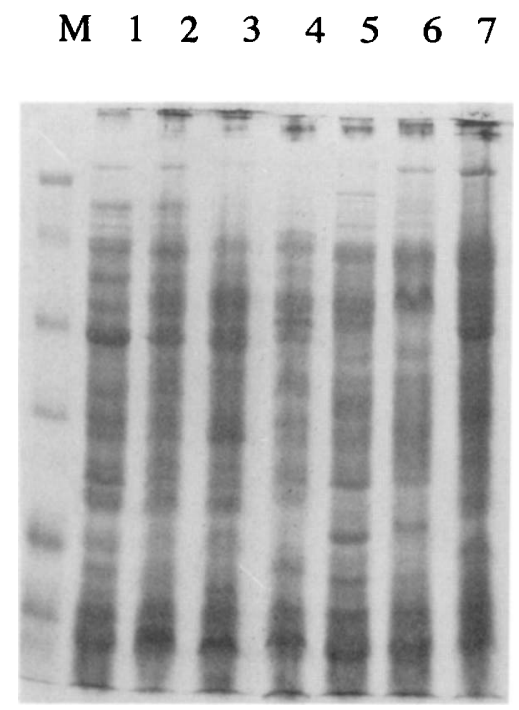

FIG. 1. SDS-PAGE profiles of type strains of Veillonella species. Lanes: 1, $V$. atypica ATCC $17744^{\mathrm{T}} ; 2, V$. parvula ATCC $10790^{\mathrm{T}} ; 3, V$. dispar ATCC $17748^{\mathrm{T}}$, 4 , V. rodentium ATCC $17743^{\mathrm{T}}$; 5, V. criceti ATCC $17747^{\mathrm{T}} ; 6$, V ratti ATCC $17746^{\mathrm{T}} ; 7, \mathrm{~V}$. caviae ATCC $33540^{\mathrm{T}} ; \mathrm{M}$, molecular mass markers $(95,68,39,29$, 20.4 , and $14 \mathrm{kDa}$ )

* Corresponding author. Mailing address: Department of Oral Microbiology, Niigata University School of Dentistry, Gakkocho-dori 2, Niigata 951, Japan. Phone: 81-25-223-6161, ext. 4165. Fax: 81-25-2288771. E-mail: tak@dent.niigata-u.ac.jp. distinguished by $16 \mathrm{~S}$ rDNA sequence comparison $(11,12)$ Conventional phenotypical and biochemical tests have been unable to distinguish Veillonella species (9). The protein profiles of Veillonella species are distinct, and determination of protein profiles is the recommended method for identifying the species of isolates within this genus $(4,10)$; this is consistent with the results of this study. In this study, sodium dodecyl sulfate-polyacrylamide gel electrophoresis (SDS-PAGE) analyses were performed as described previously (7), and Fig. 1 shows that SDS-PAGE can be used to distinguish Veillonella species.

In this study, restriction fragment length polymorphism analysis of PCR-amplified $16 \mathrm{~S}$ ribosomal DNA (16S rDNA PCR-RFLP) was used to generate restriction profiles of the type strains of the genus Veillonella, because this method can be used to identify species within some genera $(1,6,8,13,14)$.

V. atypica ATCC $17744^{\mathbf{T}}$, V. dispar ATCC $17748^{\mathbf{T}}$, V. parvula ATCC $10790^{\mathrm{T}}$, V. caviae ATCC $33540^{\mathrm{T}}$, V. criceti ATCC $17747^{\mathrm{T}}, V$. rodentium ATCC $17743^{\mathrm{T}}$, and $V$. ratti ATCC $17746^{\mathrm{T}}$ were obtained from the American Type Culture Collection. Twenty-eight fresh clinical strains, i.e., A6, A7, A30, A33, D76, D77, D78, D79, D81, D91, D92, G1, G2, G3, G4, G5, G6, G7, G8, G9, G10, G11, G12, G13, G14, G15, G16, and G17, were isolated from dental plaque from 19 volunteers and patients. They were identified to the species level by morphological and biochemical tests, including bacterial end product analysis by gas chromatography (3) and API ZYM (Rapid ID 32A) anal-

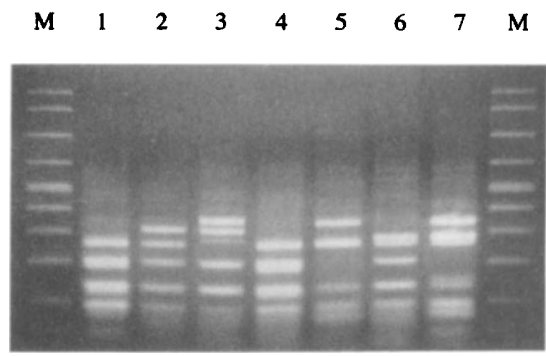

FIG. 2. Amplified 16S rDNA from type strains of Veillonella species digested with $M n l$ I. Lanes: $1, V$. atypica ATCC $17744^{\mathrm{T}} ; 2, V$. dispar ATCC $17748^{\mathrm{T}} ; 3$. V. parvula ATCC $10790^{\mathrm{T}} ; 4$, V. caviae ATCC $33540^{\mathrm{T}} ; 5, V$. criceti ATCC $17747^{\mathrm{T}}$; 6 , $V$. rodentium ATCC $17743^{\mathrm{T}} ; 7, V$ ratti, ATCC $17746^{\mathrm{T}} ; \mathrm{M}$, molecular size markers $(2,000,1,500,1,000,700,525,500,400,300,200,100$ and $50 \mathrm{bp}$; BioMarker EXT: BioVentures). 


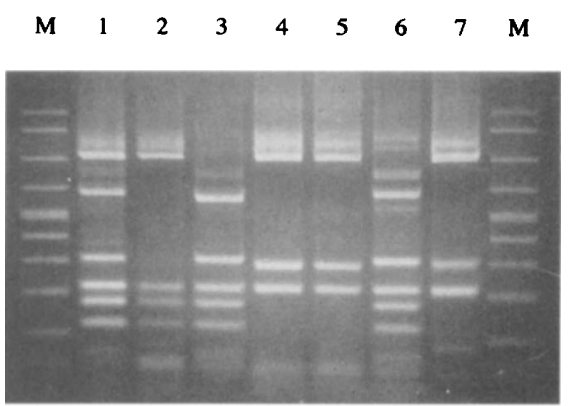

FIG. 3. Amplified 16S rDNA from type strains of Veillonella species digested with Sau3AI. Lanes are as defined in the legend for Fig. 2.

ysis and SDS-PAGE analysis (7). As a result, all of the 28 fresh isolates in this study were identified as $V$. parvula. All strains were cultured on brain heart infusion-yeast extract-blood (sheep) agar plates (2) and incubated at $37^{\circ} \mathrm{C}$ for 3 days in an anaerobic glove box (model AZ-Hard; Hirasawa, Tokyo, Japan) containing $80 \% \mathrm{~N}_{2}, 10 \% \mathrm{H}_{2}$, and $10 \% \mathrm{CO}_{2}$.

From 3-day-old cultures, DNA was extracted with the InstaGene Matrix (Bio-Rad) according to the manufacturer's instructions. The $16 \mathrm{~S}$ rRNA gene sequences were amplified by PCR with primers $27 \mathrm{f}$ and $1492 \mathrm{r}(6,13)$ and Taq DNA polymerase (Takara Premix Taq; TaKaRa Biomedicals, Shiga, Japan) according to the manufacturer's instructions. The primer sequences were as follows: 27f, 5'-GTG CTG CAG AGA GTT TGA TCC TGG CTC AG-3'; and 1492r, 5'-CAC GGA TCC TAC GGG TAC CTT GTT ACG ACT T-3'. PCR amplification was performed in a DNA thermal cycler (PTC-100; MJ Research). The temperature profile included 35 cycles, each consisting of a template denaturation step at $94^{\circ} \mathrm{C}$ for $1 \mathrm{~min}$, a primer annealing step at $52^{\circ} \mathrm{C}$ for $1 \mathrm{~min}$, and an extension step at $72^{\circ} \mathrm{C}$ for $2 \mathrm{~min}$. PCR products were detected by $0.8 \%$ agarose gel electrophoresis in Tris-acetate-EDTA buffer. The gel was stained with ethidium bromide and photographed under UV light. BioMarker EXT (BioVentures) was used as the molecular size marker.

PCR products were purified with the SpinBind PCR purification system (FMC BioProducts, Rockland, Maine). Purified $16 \mathrm{~S}$ rRNA genes were digested singly with restriction endonucleases, i.e., HaeIII, MnlI, or Sau3AI (New England Biolabs, Beverly, Mass.) according to the manufacturer's instructions. Digestion products were separated by $2 \%$ agarose (NuSieve 3:1 agarose; FMC BioProducts) gel electrophoresis in Trisborate-EDTA buffer. The gel was stained with ethidium bromide and photographed under UV light.

RFLP patterns for the $16 \mathrm{~S}$ rDNA PCR products from the

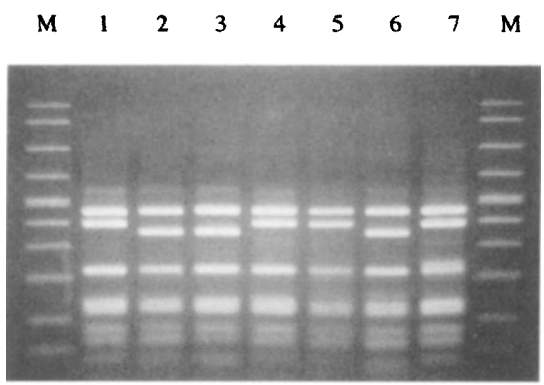

FIG. 4. Amplified 16S rDNA from type strains of Veillonella species digested with HaelII. Lanes are as defined in the legend for Fig. 2.
TABLE 1. 16S rDNA PCR-RFLP profiles of type strains of the genus Veillonella

\begin{tabular}{lccc}
\hline \multirow{2}{*}{ Strain } & \multicolumn{3}{c}{ 16S rDNA PCR-RFLP profiles } \\
\cline { 2 - 4 } & MnlI & Sau3AI & Hae III \\
\hline V. atypica ATCC $17744^{\mathrm{T}}$ & $\mathrm{A}$ & $\mathrm{A}$ & $\mathrm{A}$ \\
$V$. dispar ATCC $17748^{\mathrm{T}}$ & $\mathrm{B}$ & $\mathrm{B}$ & $\mathrm{B}$ \\
$V$. parvula ATCC $10790^{\mathrm{T}}$ & $\mathrm{C}$ & $\mathrm{C}$ & $\mathrm{B}$ \\
$V$. caviae ATCC $33540^{\mathrm{T}}$ & $\mathrm{A}$ & $\mathrm{D}$ & $\mathrm{A}$ \\
$V$. criceti ATCC $17747^{\mathrm{T}}$ & $\mathrm{D}$ & $\mathrm{D}$ & $\mathrm{A}$ \\
$V$. rodentium ATCC $17743^{\mathrm{T}}$ & $\mathrm{E}$ & $\mathrm{E}$ & $\mathrm{B}$ \\
$V$. ratti ATCC $17746^{\mathrm{T}}$ & $\mathrm{F}$ & $\mathrm{D}$ & $\mathrm{A}$ \\
\hline${ }^{a}$ 16S rDNA PCR-RFLP profiles were obtained in this study (Fig. 2 to 4).
\end{tabular}

seven type strains obtained with the three enzymes, i.e., $M n l I$, Sau3AI, and HaeIII, are shown in Fig. 2 to 4. Among the three restriction endonucleases, $M n l l$ produced six RFLP patterns for seven reference strains, since the patterns for $V$. atypica and $V$. caviae were the same (Fig. 2, lanes 1 and 4). In contrast, RFLP patterns produced with Sau3AI could separate the two species (Fig. 3, lanes 1 and 4). Sau3AI produced five patterns, since the patterns for $V$. caviae, $V$. criceti, and $V$. ratti were the same (Fig. 3, lanes 4, 5, and 7). HaeIII produced two patterns, since the patterns for $V$. atypica, $V$. caviae, $V$. criceti, and $V$. ratti were the same (Fig. 4, lanes 1, 4, 5, and 7) and those for $V$. dispar, $V$. parvula, and $V$. rodentium were the same (Fig. 4, lanes 2, 3, and 6). The combination of the results of $16 \mathrm{~S}$ rDNA PCR-RFLP using $M n l I$ and Sau3AI allowed the seven American Type Culture Collection type strains to be distinguished from one another (Table 1).

Twenty-eight fresh clinical strains, identified as $V$. parvula by conventional methods, were assigned to $V$. parvula (data not shown). Further studies, including large-scale studies with more clinical isolates, to confirm the usefulness of this $16 \mathrm{~S}$ rDNA PCR-RFLP method are clearly required.

The 16S rRNA gene sequences from strains of three species of Veillonella, i.e., V. atypica DSM 20739, V. dispar DSM 20735 , and $V$. parvula DSM 2008, were accessed from the GenBank. The expected sizes of the restriction fragments (at least $100 \mathrm{bp}$ long) digested with $M n l \mathrm{I}$ are as follows: $V$. atypica, 260, 205, 190, 135, 126, and $107 \mathrm{bp} ; V$. dispar, 316, 260, 205, 135, and 107 bp; and $V$. parvula, 354, 316, 205, and 107 bp. For digestion with Sau3AI, they are as follows: $V$. atypica, 659, 308, 216, 155 , and $116 \mathrm{bp} ; V$.dispar, 1,026, 216, and $155 \mathrm{bp}$; and $V$. parvula, $368,308,216,172,155$, and 116 bp. For digestion with HaeIII, they are as follows: $V$. atypica, 459, 392, 191, 133, and $121 \mathrm{bp}$; $V$. dispar, 459, 354, 191, 133, and $121 \mathrm{bp}$; and $V$. parvula, 459, $354,191,133$, and $121 \mathrm{bp}$. The RFLP patterns obtained in this study (Fig. 2 to 4 ) are in accordance with the restriction profiles expected, except for those for $V$. atypica and $V$. parvula digested with Sau3AI.

Takuichi Sato and Junko Matsuyama were recipients of the JSPS Research Fellowships for Young Scientists (no. 3781 and 0143, respectively). This study was supported in part by The Japanese Ministry of Education, Science, Sports and Culture under grants-in-aid for JSPS fellows (no. 3781 to T.S.; no. 0143 to J.M.) and for scientific research (no. 07307018).

\section{REFERENCES}

1. Borrell, N., S. G. Acinas, M.-J. Figueras, and A. J. Martínez-Murcia. 1997. Identification of Aeromonas clinical isolates by restriction fragment length polymorphism of PCR-amplified 16S rRNA genes. J. Clin. Microbiol. 35: 1671-1674.

2. Holdeman, L. V., E. P. Cato, and W. E. C. Moore. 1977. Anaerobe laboratory manual, 4th ed. Virginia Polytechnic Institute and State University, Blacksburg, Va. 
3. Hoshino, E., and M. Sato. 1986. Production and degradation of formate by Veillonella dispar ATCC 17745. J. Dent. Res. 65:903-905.

4. Kolenbrander, P. E., and L. V. H. Moore. 1992. The genus Veillonella, p. 2034-2047. In A. Balows, H. G. Trüper, M. Dworkin, W. Harder, and K.-H. Schleifer (ed.), The prokaryotes, 2nd ed. Springer-Verlag, New York, N.Y.

5. Mays, T. D., L. V. Holdeman, W. E. C. Moore, M. Rogosa, and J. L. Johnson. 1982. Taxonomy of the genus Veillonella. Int. J. Syst. Bacteriol. 32:28-36.

6. Milsom, S. E., S. V. Sprague, D. Dymock, A. J. Weightman, and W. G. Wade 1996. Rapid differentiation of Prevotella intermedia and P. nigrescens by $16 \mathrm{~S}$ rDNA PCR-RFLP. J. Med. Microbiol. 44:41-43.

7. Poco, S. E., Jr., F. Nakazawa, T. Ikeda, M. Sato, T. Sato, and E. Hoshino. 1996. Eubacterium exiguum sp. nov., isolated from human oral lesions. Int. J. Syst. Bacteriol. 46:1120-1124.

8. Riggio, M. P., and A. Lennon. 1997. Rapid identification of Actinobacillus actinomycetemcomitans, Haemophilus aphrophilus, and Haemophilus paraphrophilus by restriction enzyme analysis of PCR-amplified 16S rRNA genes. J. Clin. Microbiol. 35:1630-1632.

9. Rogosa, M. 1984. Genus I. Veillonella Prévot 1933, 118, emend. mut. char.
Rogosa 1965, 706 AL, p. 681-683. In N. R. Krieg and J. G. Holt (ed.), Bergey's manual of systematic bacteriology. Williams \& Wilkins Co., Baltimore, Md.

10. Tanner, A. C.-H. Lai, and M. Maiden. 1992. Characteristics of oral gramnegative species, p. 299-341. In J. Slots and M. A. Taubman (ed.), Contemporary oral microbiology and immunology, Mosby-Year Book, St. Louis, Mo.

11. Tanner, A. M. F. J. Maiden, B. J. Paster, and F. E. Dewhirst. 1994. The impact of $16 \mathrm{~S}$ ribosomal RNA-based phylogeny on the taxonomy of oral bacteria. Periodontol. 2000 5:26-51.

12. Willems, A., and M. D. Collins. 1995. Phylogenetic placement of Dialister pneumosintes (formerly Bacteroides pneumosintes) within the Sporomusa subbranch of the Clostridium subphylum of the gram-positive bacteria. Int. J. Syst. Bacteriol. 45:403-405.

13. Wilson, M. J., W. G. Wade, and A. J. Weightman. 1995. Restriction fragment length polymorphism analysis of PCR-amplified 16S ribosomal DNA of human Capnocytophaga. J. Appl. Bacteriol. 78:394-401.

14. Yoon, J.-H., S. T. Lee, S.-B. Kim, W. Y. Kim, M. Goodfellow, and Y.-H. Park. 1997. Restriction fragment length polymorphism analysis of PCR-amplified 16 S ribosomal DNA for rapid identification of Saccharomonospora strains. Int. J. Syst. Bacteriol. 47:111-114. 